\title{
Analysis and forecast of ensuring the reliability of the Kyrgyz energy system in the draft of "Concept for the development of energy in the long-term perspective
}

\author{
Valentina Kasymova ${ }^{1}$, Anna Arkhangelskaya ${ }^{2}$, and Roza Kurzhumbaeva ${ }^{1}$ \\ ${ }^{1}$ Kyrgyz National technical university named after I. Razzakov, 66 Mir av., Bishkek, Kyrgyz Republic \\ ${ }^{2}$ Governmetal committee of industry, energy and subsoil use of the Kyrgyz Republic, 720000, 2 Erkindik str., Bishkek, Kyrgyz \\ Republic
}

\begin{abstract}
In this article, based on the work done to prepare the project of the Concept of development of the fuel and energy complex of the Kyrgyz Republic until 2030 identifies the main directions for the development of the country's energy sector in the medium-term perspective, including ensuring sustainable and uninterrupted electricity and fuel supply for the development of the economy and population needs, the introduction of new technologies using renewable energy sources, institutional reforms, financial recovery of energy companies, etc. In addition, the main priorities of the state energy policy, priority tasks and policy measures on scenarios are outlined.
\end{abstract}

\section{Introduction}

The Kyrgyz Republic (KR) has sufficient reserves of fuel and energy resources (FER). However, the potential of the fuel and energy complex (FEC) is not being realized in sufficient measure. The fuel and energy complex of the Kyrgyz Republic, which is the main sector in ensuring sustainable social and economic development of the country, is currently in crisis [4]. An assessment of the state's energy policy shows the presence of threats to the country's energy security, including regions, caused by both external and internal factors. In addition to rising global prices for hydrocarbon fuels, disagreements in the Central Asian region are one of the main external factors, especially disagreements with neighboring countries on the introduction of economic mechanisms in the management of water and energy resources in the basin of the Naryn and Syrdarya rivers. Internal factors of threats are the irrational structure of the country's fuel and energy balance (FEB); low economic indicators of the development of enterprises in the fuel and energy sector, the manifestation of corruption schemes, physical and moral deterioration of the main equipment at the facilities, high energy losses, chronic financial shortages, increased accidents in power networks and, as a result, shutdown and shortage of energy carriers to consumers, which leads to lost profits in the country's economy and the growth of social tensions in society.

\section{Main statements of the 'Concept for the Development of the Fuel and Energy Complex of the Kyrgyz Republic until 2030'}

In order to increase the efficiency of the development of the fuel and energy complex in pursuance of the Detailed Plan for Implementing Measures to Counter Systemic Corruption in the Energy Sector of the Kyrgyz Republic, the draft Concept for the Development of the Fuel and Energy Complex of the Kyrgyz Republic until 2030 (hereinafter referred to as the Concept) was drafted on March 5, 2014.

The concept was developed in accordance with the Laws of the Kyrgyz Republic "On Energy", "On Electric Power", "On Oil and Gas", "On Coal", "On Energy Conservation", "On Renewable Energy Sources", regulating the country's fuel and energy complex and the National Energy Program for 2008-2010 and the strategy for the development of the fuel and energy sector until 2025; and also on the basis of the methodology for strategic planning of sustainable development approved by the order of the Minister of Economy of the Kyrgyz Republic No. 45 of February 27, 2015.

Over the past 10 years, the state policy on the development of FEC is carried out in accordance with the National Energy Program of the Kyrgyz Republic for 2008-2010 and the strategy for the development of the fuel and energy complex until 2025, the Medium-Term Strategy for the Development of the Electric Power Industry of the KR for 2012-2017, the National Strategy for Sustainable Development of the KR for the period $2013-2017$ years. 
Due to the expiration of their term and methodology of system research in power engineering, the concept and development strategy should be updated (every 5 years) based on the real situation in the social and economic development of the state and challenges in the external energy policy, as well as global environmental problems.

The high capital intensity and long terms of the construction of power facilities makes the outstrip development of energy in order to ensure the industry, agriculture, construction, transport and social needs of the population with uninterrupted energy and fuel supply.

In addition, the annual complex situation with reliability associated with the unstable provision of energy resources to the consumers of the republic requires the adoption of strategic decisions on the development of fuel and energy industries for the short, medium and long term (10-15 years). [3]

In the draft Concept, the main sectoral and cross-sectoral programs and plans of social and economic development of the country and regions were used.

In accordance with the fundamentals of systemic research in the energy sector [1] and the Strategic Planning Methodology for Sustainable Development (hereinafter the Methodology) [2], the draft Concept contains the following sections: analysis and assessment of the current situation in providing fuel and energy energy policy; priority tasks and policy measures; expected results; assessment of risks and challenges; assessment of financial resources and sources of funding; mechanisms and responsible bodies for the implementation of the concept.

At the same time, the requirements of the Methodology on accounting for regional, social, environmental factors, ensuring energy security and energy efficiency of the real sector of the economy, and advancing along the path of sustainable development of the country and regions were taken into consideration. Proceeding from this, we determined the purpose of the Concept - to ensure the energy security of the country and regions, the availability of energy for each consumer in terms of quality and prices, and improving the living standards of the population, achieving energy efficiency of the real economy and sustainable development of the country and regions in the future.

Based on the goal, priorities are formulated and tasks are set, with successful implementation of which it is possible to achieve the goal and obtain results.

The following priorities are recognized as the main priorities of the state energy policy:

- management of demand for energy resources and achievement of energy efficiency of the economy, formation of a rational structure of the country's and regions' FEBs,

- Sustainable energy development: ensuring reliability and energy security, as well as reducing the risks of climate change;
- international cooperation and strengthening of the external energy policy

- financial recovery with the introduction of an economically sound tariff policy, ensuring financial stability and efficiency of energy companies and energy companies;

- energy saving and minimizing the technogenic impact of energy on the environment, public health and progress towards sustainable development of the country and regions;

- institutional reforms: strengthening of strategic management, regulatory legal framework and innovative development of energy,

- improving the quality of education and research.

Priority objectives and policy measures

1. Priority tasks "Managing energy demand and achieving energy efficiency of the economy, formation of a rational structure of the country's and regions' FEBs include, first of all, ensuring the energy efficiency of the real sector of the economy, which will be achieved with the projected growth rates of consumption in the FEC - 150\% in 2020 and $210 \%$ in 2030 to 2005 , which is below the GDP growth rate of $197 \%$ in 2020 and $320 \%$ in 2030 to 2005 (in comparable prices in 2005), with an annual decline in the energy intensity of GDP by $1.5 \%$, and for the period $2015-2030$ on $20 \%$. At the same time, it is possible to achieve energy savings in the amount 11.1 million tons of tones by 2030 .

The growth rate of electricity consumption should also be lower than GDP growth, with an annual decline in the GDP electric capacity by 1 $1.6 \%$, and for the period $2015-2030$ on $15-19 \%$ under the different scenarios. At the same time, energy savings in volume $3.65-4.1$ billion $\mathrm{kWh}$ by 2030 is expected.

Ensuring a decrease in the growth rates of fuel and energy consumption, in comparison with the growth rates of GDP and, accordingly, the regularity of the annual rate of reduction in energy intensity and GDP electrical capacity, meets the principles of energy-saving policies and the development of the "green economy". If the GDP growth rate increases, the forecasted demand for fuel and energy resources will also increase, in this case the degree of increase will depend on the prices for energy carriers - the more their growth, the less the degree of increase in demand. [4]

2. Priority tasks "Sustainable energy: ensuring energy security and preventing global warming" should be directed to:

2.1. In the electric power industry:

- the development of hydropower, which is an integral part of the "green economy" and the most important prerequisite for sustainable development, with access to modern, environmentally friendly and inexpensive energy services;

- creating a system for assessing the state of the country's EE, which requires the development and approval of indicators and their thresholds - crisis and pre-crisis - as an important tool for timely warning of threats; 
- outstripping the pace of commissioning new capacities of power plants and guaranteeing the level of the reserve of installed HPP capacities in the power system;

- a phased implementation of a number of projects on the construction of hydroelectric power stations on its territory that are environmentally friendly energy sources, which is a sovereign right to development to meet the pressing needs of the people of Kyrgyzstan, including future generations;

- further integrated use of water resources in the Naryn river basin with gradual transition to the project mode of operation of the Toktogul HPP in the interests of energy and irrigation and not allowing the Toktogul reservoir to run to a critical level by implementing projects for the construction of the Kambarata HPP-1 installed capacity of 1860 MW in the power mode to cover the demand of the country's consumers in the autumn-winter period. As a result, the winter energy releases of water from the Kambarata HPPs will accumulate and will be re-regulated by the Toktogul reservoir under the irrigation schedule for water consumption, that is, the operation of Kambarata HPP-1 will correct seasonal inflow into the Toktogul reservoir and, therefore, allow sufficient quantities in the most droughty seasons water adjacent countries-lower reaches;

- acceleration in 2017-2019 years installation of the second aggregate of Kambarata HPP-2 with a capacity of $120 \mathrm{MW}$;

- Considering the possibilities of construction in the middle reaches of the Naryn River basin of the Kazarman cascade of HPPs in 2025-2030 years with a total capacity of $1050 \mathrm{MW}$, as well as the Susamyr-Kokemerens cascade of HPPs with a total installed capacity of 1,305 MW;

- development of the hydropotential of the SaryJaz river basin;

- Construction in 2019-2025 years HigherNaryn cascade of HPPs with an installed capacity of 237.7 MW;

- Creation of guaranteed base capacity in the power system with the construction in 2018-2022 years Kara-Keche TPP with an installed capacity of $600 \mathrm{MW}$, followed by expansion to $1200 \mathrm{MW}$;

- Completion of the reconstruction in 2017 of TPP-1 in Bishkek with the installation of 2 boilers of $150 \mathrm{MW}$ each and an increase in power to 812 MW;

- Conducting and completing the reconstruction of the Uchkurgan HPP - on $36 \mathrm{MW}$, Atbashi HPP by $1.68 \mathrm{MW}$, Toktogul HPP to increase capacity by $240 \mathrm{MW}$;

- Development of a procedure for the allocation of land and the implementation of tariff policy in accordance with the Law of the Kyrgyz Republic "On Renewable Energy Sources";

- Increasing the efficiency and reliability of the district heating system in Bishkek, carrying out the rehabilitation work of the existing main heating network and constructing new heating networks and pumping stations in the operation area of TPP-2 in Bishkek.

Based on the forecasts of the growth rates of consumption of the fuel and energy resources for their coverage, the forecasts of the development of the fuel and energy sectors were developed according to scenarios that showed:

In the electric power industry: according to the baseline scenario, the growth in electricity production can be achieved through the active involvement of renewable energy sources and the construction of small HPP and solar power plants (SES), taking into account the construction and commissioning of the Higher-Naryn cascade of HPPs and Kambarata HPP-1, the growth rate of electricity production is $119 \%$ by $2020,140 \%$ by 2025 and $246 \%$ by 2030 ? or up to $16.7,23.8$ and 27 billion $\mathrm{kWh}$, respectively, over the growth rate of its consumption since 2020 or $119 \%$ to $140 \%$ by 2025 , and $166 \%$ by 2030 .

At the same time, the ratio of the growth rates of production over the growth rates of consumption will amount to 0.9 by $2020,1.11$ by 2025 and 1.48 in 2030 , in this case it will be possible to provide a basic reserve of capacity in the power system within up to $48 \%$, that is, the reserve in the power system is expected to exceed the threshold threshold value of 1.15 .

According to the optimistic scenario, new approaches to forecast the development of the regions of the country have been taken into account by accelerating the development of enterprises for processing plant and livestock products, developing mineral and raw materials resources and forming mining, sports, tourist and agricultural clusters, as well as the rates of growth in prices and tariffs for energy, using econometric forecasting models under the STATA program, and additional expert assessments. The demand for electricity will increase annually and will reach the level of 14.87 billion $\mathrm{kWh}$ by $2020,19.5$ billion $\mathrm{kWh}$ by 2025 and up to 23.0 billion $\mathrm{kWh}$ by 2030 , or, respectively, over the years, growth rates are expected - 124\%, 163\% and 193\% compared to 2017. The growth rate and the volume of electricity production during the construction of the Kazarman HPPs will increase and will reach $172 \%$ by 2025 and $253 \%$ by 2030 or up to 27 and 33.3 billion $\mathrm{kWh}$, respectively. The ratio of the growth rates of production over the growth rates of consumption will increase from 2020 and are expected to be 1.1 by 2025 and 1.31 to 2030 , and in this case it will be possible to provide a basic capacity reserve in the power system within $30 \%$, which will completely eliminate the energy security risks and cover the growing energy consumption rates in the regions of the country.

In the structure of electricity production, the share of RES will increase from $1.1 \%$ in 2015 to $5.0 \%$ by 2030 .

To ensure the reliability of power supply in remote mountain areas, it is possible to build small thermal power plants when introducing new 
technologies for coal combustion with minimal GHG emissions. When constructing small TPPs in cogeneration mode in the region of Sulukta coal fields with a capacity of $75 \mathrm{MW}$ in the Batken region, Tashkumyr with a capacity of $75 \mathrm{MW}$ in Jalal-Abad region, Uzgen, Kyzyl-Kiya with a capacity of $50 \mathrm{MW}$ in the Osh region, it is possible to generate additional electricity within 1,5-2 billion kWh by 2030 with the growth of their share also up to $5.4 \%$ in the electricity balance.

2.2. Accelerated development of renewable energy sources for diversification of electric power sources that can largely provide energy resources to both large and individual consumers, especially in rural areas, is provided by: construction of solar and wind power plants in the regions of the country with a gradual increase in electricity production by them to 1.2 billion $\mathrm{kWh}$ by 2030 ; introduction of biogas plants to produce biogas and with the associated use of waste as fertilizer for farms.

To solve the problems of hot water supply and heat supply in residential houses, the installation of solar collectors, heat pumps, and the use of heat from geothermal sources for the heat supply of social and cultural facilities and the population in the areas where they are concentrated is necessary.

In parallel with the search for investors in the construction of solar and wind power plants and the construction of small hydro power plants, it is necessary to determine the sources of coverage for the difference between electricity tariffs and tariffs, taking into account the coefficients in accordance with the Law of the Kyrgyz Republic "On Renewable Energy Sources" in order to pay for RES projects.

2.3. In order to adapt and mitigate to climate change, the development of small and large HPPs with efficient use of solar energy, biomass, geothermal sources and heat pumps with replacement of hydrocarbon fuels can reduce GHG emissions by $20 \%$ by 2020 and the attainment of the set goals for achieving by 2050. Specific emissions in $\mathrm{CO}_{2}$ equivalent, not exceeding 1.56 tons per person according to the Climate Center under the SAEPF with the RCC.

For these purpose it is needed:

- the introduction on an ongoing basis of climate indicators for the energy sector and their monitoring;

- regular preparation of plans to fulfill commitments to the UNFCCC on reducing greenhouse gas emissions;

- intensification of activities to attract climate finance to ensure energy security.

3. Priority tasks - international cooperation and strengthening of the external energy policy will take place by entering the international electricity markets, while ensuring a surplus balance of electricity. [3]

Thus, according to the baseline scenario, the forecast shows a tight balance until 2020, as well as the possibility of export only by 2025 and 2030 in the volume of over 4 billion $\mathrm{kWh}$, including
1,7 billion $\mathrm{kWh}$ for the CASA-1000 project and over 2 billion $\mathrm{kWh}$ into the energy systems of the EEA countries to the wholesale electricity market and (or) the PRC; according to the optimistic, as under the baseline scenario, reduction of imports up to 2018 , further it is possible to increase exports to 0.23 billion $\mathrm{kWh}$ by $2020,4.4$ billion $\mathrm{kWh}$ by 2025 and up to 6.3 billion $\mathrm{kWh}$ by 2030, which will also allow entering the unified electricity market of the EAPS with an export volume of over 3 billion $\mathrm{kWh}$ and the Central and South Asia market for the CASA-1000 project - 1.7 billion $\mathrm{kWh}$ and 1.5 billion kWh in the PRC.

There is also an opportunity to increase exports during the construction of the SusamyrKokomerene cascade of HPPs with a design capacity of 1,305 MW, generating 3.32 billion $\mathrm{kWh}$ per year and a hydroelectric power station on the Sary-Jaz river with total design capacity up to 1200 MW with generation up to 3.3 billion $\mathrm{kWh}$ per year. However, given the lack of pre-project documentation, these HPPs were not included in the prospective electricity balance until 2030 and can be considered when developing an energy strategy until 2040.

The necessary investments for the construction and commissioning of the capacities of prospective HPPs and TPPs and $500 \mathrm{kV}$ transmission lines are:

- Under the base scenario of development - \$ 6597 million;

- According to the optimistic scenario of development - \$8878.85 million.

Necessary investments in the development of transmission electric networks for 2017-2030 amount of \$ 420.6 million.

The need for investment in small hydropower plants is estimated in $\$ 350$ million, at the rate of $\$$ 1000 per $1 \mathrm{MW}$ of capacity, small-scale thermal power plants - \$250 million.

4. Tasks for financial recovery with the introduction of an economically sound tariff policy, ensuring financial stability and efficiency of energy companies should be aimed at:

- ensuring economic efficiency and financial sustainability of energy companies and enterprises in the coal and oil and gas industries;

- introduction of a system of key indicators of energy security, efficiency and financial stability, increasing the efficiency of energy companies for their regular monitoring and media coverage for the public and the public;

- conducting a portfolio analysis of energy companies using matrices from international practice, identifying external and internal threats, weak and strong points, finding reserves and opportunities to withdraw them from the financial crisis;

- Introduction of an automated system of management accounting in energy companies, taking into account international experience for ensuring transparency and counteracting corruption;

- development and approval of the Methodology for the formation of tariffs for regulated energy 
carriers with a transparent mechanism for establishing purchase tariffs for electricity and heat between the energy companies for the production, transmission and distribution of electricity and heat, ensuring their break-even and full reimbursement of objectively necessary costs, with the elimination of the existing practice of income distribution and cross- subsidizing;

- development and approval of the method of technological connection of consumers to electric and heat networks and fees for connection to power supply and heat supply systems for new facilities consumers;

- maintenance of a share of the per capita income of the population spent for payment of power resources, is not higher than threshold values of energy security (20-30\%);

- Conducting a revaluation of fixed assets with an increase in depreciation charges for the technical modernization and reconstruction of transmission and distribution lines and reducing the level of depreciation of fixed assets at facilities for the production, transmission and distribution of electricity.

5. Priority tasks "Institutional reforms: strengthening of strategic management, regulatory framework and innovative development of energy" should focus on Realization of the program of stage-by-stage reforming of organization and management of the electric power industry of the KR:

- development of the draft Concept of energy security and implementation of the Strategy for the Development of the Electricity Industry of the KR for 2018-2023 and long-term perspective up to 2030-2040;

- development and implementation of the Strategy for the development of the fuel industry of the KR for 2018-2023 and long-term perspective up to 2030-2040;

- development and implementation of the Strategy for the Development of RES of the KR for 2018-2023 and long-term perspective up to 20302040;

- Conducting systematic monitoring of the state of energy security by indicators and compliance with threshold values approved in legislation;

- Improvement of strategic management and management in NEFIC with optimization of costs in the activities of energy companies.

Concentration on priority and innovative directions of development of the energy science, strengthening of the scientific and personnel potential by:

- creation of a system for introducing the results of scientific and technical activities into the practice of the development and operation of the electricity and energy industry using various forms of publicprivate partnerships, supporting small and mediumsized businesses;

- introduction of innovative technologies (ASIS, SCADA, CIP wires, relay protection and automation, smart meters, etc.) in order to increase the efficiency of transmission and distribution of electricity to the consumer, reduce losses and improve the quality of electricity, including for urban and the rural population in the regions;

- reduction of the technological consumption of electric power to their standard values for transmission (5\%) and distribution (10\%).

6. The tasks on the priority of improving the quality of education and scientific research should be achieved by:

- Increasing on a systematic basis the qualification of engineering, technical, economic and financial personnel of energy companies of the KSTU. Named after I. Razzakov together with leading universities of Russia, to ensure crisis management and management of energy companies;

- Increase the level of training in higher education institutions of the country by way of exchange for teaching students and improving curricula and programs in the disciplines of specializations; and the restoration of the training of engineers in universities and the opening of new areas of magistracy;

- Strengthening of scientific system research in the energy sector and their constant updating, using economic and mathematical methods for forecasting the development of energy systems and optimizing EBs and software in the Science research institute on energy and economics and KSTU with the assistance of the Institute of Power Systems named after. L.A. Melentiev.

\section{Conclusion}

Given the limited nature of the publication, we focused only on the main directions of the draft Concept. It should be noted that, in order to realize it, expected results are expected with an assessment of the necessary financial resources, an Action Plan and a Matrix of indicators have been developed, and the forecasted values of indicators for the future have been modeled.

The Draft Concept presented for consideration and approval is a strategic document that provides a set of mechanisms for public administration and regulation for the efficient and rational use of energy resources, ensuring the advanced development of energy capacities, including renewable energy sources, the implementation of energy-saving policies and sustainable development goals.

The approval of the draft Concept by the Government of the Kyrgyz Republic will help confidence of potential investors that the strategically important objects of interest are included in the state program and are a guarantee of return of the capital invested with profit. 


\section{References}

1. L.A. Melentiev, Optimization of development and management of large energy systems. - M: High School, (1976).

2. Methodology for strategic planning of sustainable development of the Kyrgyz Republic. Approved by the order of the Minister of Economy of the Kyrgyz Republic No. 45 of February 27, 2015.

3. Russia's energy policy at the turn of the century; Priorities of energy policy: from energy security to energy diplomacy. (T.2. - M .: "Papyrus PRO", 2001).

4. V.M. Kasymova, Energy policy. energy security and energy efficiency of the Kyrgyz Republic. Bishkek, KSTU named after I.Razzakov, publishing house "BarakElde", (2015).

5. V.M. Kasymova, A.V. Arkhangelskaya R.B. Kurzhumbaeva, Scientific foundations of the state concept of energy policy and development strategy of the fuel and energy complex of the Kyrgyz Republic until 2030. KSTU named after I.Razzakov, publishing house "Barak Elde", Bishkek, (2017). 